\title{
Alcohol y metabolismo humano
}

\author{
Aragón, C.; Miouel, M.; Correa, M.; Sanchis-Segura, C. \\ Área de Psicobiología. Universitat Jaume I. Castelló.
}

Enviar correspondencia a: Carlos Aragón. Universitat Jaume I. Area de Psicobiología. Campus de Borriol. 8029 AP Castelló

\section{RESUMEN}

Uno de los propósitos del presente trabajo es llevar a cabo una revisión actualizada y resumida de los aspectos más relevantes de los procesos de absorción, distribución, biotransformación (metabolismo) y excreción del alcohol. Aunque con variaciones individuales importantes, el alcohol se absorbe mayoritariamente a nivel intestinal, se distribuye por el organismo de forma análoga a la del agua corporal, y se metaboliza en su mayor parte. Dado que la biotransformación fundamental del etanol se produce mediante un metabolismo enzimático oxidativo, hemos reservado un apartado para analizar, en la medida de lo posible, los sistemas enzimáticos responsables de dicha oxidación. Asimismo, con este capítulo hemos querido ofrecer un resumen de los datos disponibles sobre la implicación del acetaldehido, primer metabolito oxidativo del etanol, en los efectos del alcohol. Dicha implicación no se reduce, como tradicionalmente se ha creído, a los efectos tóxicos derivados del consumo de alcohol. Por el contrario, existe un corpus de conocimientos experimentales cada vez más sólido que relaciona al acetaldehido con los efectos euforizantes del alcohol y, en consecuencia, con la capacidad de esta droga de establecer un patrón de consumo repetido. Finalmente, se revisan las interacciones que pueden ocurrir entre el metabolismo del alcohol y la biotransformación de otras sustancias. Dichas interacciones pueden tener lugar siempre que sustancias endógenas o exógenas compartan con el etanol los mismos sistemas enzimáticos. En este sentido, merece especial atención la inducción del P-450 2E1 y otros citocromos P-450 en las células hepáticas provocada por el consumo crónico de alcohol.

Palabras clave: alcohol, acetaldehido, metabolismo, biotransformación.

\section{ABSTRACT}

One of the objectives of this present work is to carry out an up-to-date and summarised review of the most relevant aspects of alcohol absorption, distribution, metabolism and excretion processes. Although there are significant individual variations, alcohol is, in the main, absorbed at an intestinal level distributed by the organism in an analogous way to that of body water and most of it is metabolised. Given that the basic biotransformation of ethanol is produced by means of an oxidative enzymatic metabolism, we have set aside a section to analyse insofar as possible- the enzymatic systems responsible for such oxidisation. In addition, in this chapter, we would like to provide a summary of the data available on the involvement of acetaldehyde, primary metabolic oxidative, in the effects of alcohol. Said involvement is not limited, as was hitherto believed, to the toxic effects derived from alcohol consumption. On the contrary, there is an increasingly solid body of experimental knowledge that associates acetaldehyde with the euphoric effects of alcohol and, consequently, with the ability of this drug to establish a pattern of repeated consumption. Finally, there is a review of the interactions that can occur between the metabolism of alcohol and the biotransformation of other substances. These interactions may always lead to endogenous or exogenous substances sharing the same enzymatic systems with ethanol. In this sense, the induction of the P-450 2E1 and other P-450 cytochromes in hepatic cells, provoked by the chronic consumption of alcohol, merits particular attention.

Key words: alcohol, acetaldehyde, metabolism, biotransformation.

\section{ABSORCIÓN, DISTRIBUCIÓNY ELIMINA- CIÓN DEL ETANOL}

\subsection{Determinación de las concentraciones de etanol.}

a medición de las concentraciones de etanol en los fluidos corporales posee importantes implicaciones a nivel social, penal y médico-forense, ya que esta sustancia posee consecuencias muy significativas 
sobre la conducta y experiencia subjetiva. Así, parece claro que la determinación de la presencia y cantidad de etanol en tejidos corporales se convierten en determinantes fundamentales para delimitar la responsabilidad del individuo ante un gran número de circunstancias.

Los niveles de etanol son habitualmente medidos en términos de concentración en el torrente sanguíneo y este cociente se denomina niveles de etanol en sangre (BAC, Blood Alcohol Levels). Para estimar dichos niveles pueden tomarse muestras de sangre o, más a menudo en la praxis clínica, medir dichos niveles en el aire exhalado. Las medidas de las concentraciones de etanol desde otros fluidos corporales presentan una menor fiabilidad y son, pues, desaconsejables.

Las concentraciones de etanol en muestras biológicas presentan diversas fórmulas de notación. Así, en los trabajos científicos, los niveles de etanol se suelen informar en miligramos de etanol por decilitro (mg/dL). Sin embargo, en este tipo de trabajos también es común la notación en unidades de concentración del sistema internacional, como el milimolar (mM); $1 \mathrm{mM}$ equivale aproximadamente a $4,6 \mathrm{mg} / \mathrm{dL}$.

En estudios de corte más clínico, así como en ámbitos no científicos (legislativo, informativo, publicitario, etc), además de estas notaciones existen otras, como el porcentaje de etanol en sangre. Dicho porcentaje expresa los gramos de etanol contenidos en $100 \mathrm{ml}$ de sangre. Así, un nivel de etanol en sangre del $0.05 \%$ equivale a una concentración aproximada de $50 \mathrm{mg} / \mathrm{dL}(0.5 \mathrm{~g} / \mathrm{L})$. Esta es la unidad de medida empleada por el código circulatorio para delimitar la concentración máxima de etanol con el que se puede conducir legalmente un vehículo a motor. También en este tipo de ámbitos es habitual una medida de concentración que expresa las concentraciones de etanol en el aire exhalado. Esta medida asume un coeficiente de partición sangre:aire de 2300:1, por lo que las unidades empleadas implican la cantidad de miligramos de etanol en 230 litros (L).
En general, la concentración de etanol en sangre permite predecir el grado de modificación conductual y cognitiva de un sujeto. Así, y con carácter estimativo Bogen (1932) propuso una clasificación de los efectos del etanol esperables sobre la ejecución, según diferentes concentraciones séricas de esta sustancia. Esta clasificación se mantiene en la actualidad con escasas variaciones. Según esta clasificación, concentraciones (BACs) de:

-Entre 10 y $30 \mathrm{mg} / \mathrm{dL}$ no existe apenas alteración funcional perceptible, excepto si se recurre a procesos y tareas más sofisticados de laboratorio (ej. Tareas de atención dividida).

-Entre 30 y $60 \mathrm{mg} / \mathrm{dL}$ de etanol en sangre producen una sensación de euforia así como un incremento de la interacción social.

-Entre 60 y 100 mg /dL la euforia llega a producir desinhibición y una seria alteración del autocontrol y de la capacidad valorativa del sujeto.

-Entre 100 y $150 \mathrm{mg} / \mathrm{dL}$, concentraciones que pueden alcanzarse aún en episodios de consumo de etanol socialmente considerado como aceptable, se produce un importante descenso de la ejecución psicomotora y la articulación del habla se ve parcialmente comprometida.

-Entre 150 y 200 mg /dL de etanol en sangre producen una confusión mental significativa que se traduce incluso en dificultades relativas para mantener el equilibrio postural.

En la descripción de la concentración en bebidas alcohólicas la terminología más común implica el porcentaje de alcohol puro contenido en un volumen total de $100 \mathrm{ml}$. Este porcentaje puede implicar la relación entre volúmenes (expresado como \% v/v) O entre masa y volumen ( $\% \mathrm{w} / \mathrm{v})$.

\subsection{Rutas de administración y absorción del etanol.}

El etanol es consumido, de forma prácticamente exclusiva, por via oral. Por tanto, la 
descripción que a continuación se presenta de la absorción del mismo se hace considerando esta vía de administración.

La absorción del etanol, tras un consumo oral se produce fundamentalmente en el tracto digestivo. En este sentido, y ya que el etanol es una molécula que no puede ser ionizada, el pH de ninguno de los compartimentos del tracto digestivo parece presentar influencia alguna en este proceso.

El etanol posee un coeficiente de partición de 0.5 , aunque en el organismo se distribuye con mayor facilidad en los medios acuosos que en los lipídicos y puede acceder al torrente sanguíneo desde la cavidad oral, el esófago, el estómago, y los intestinos. En cualquier caso, a nivel cuantitativo parece que el etanol se absorbe fundamentalmente en el intestino delgado, debido a que en este órgano la presencia de microvellosidades aumentan de forma notable la superficie que posibilita dicha absorción.

La duración media del proceso gástrico de absorción del etanol ha sido cifrada en 1,7 minutos. En cualquier caso, este tiempo depende también de la dosis, ya que incrementando ésta se aumenta el tiempo de absorción. Por otra parte, existen una serie de factores que parecen afectar los procesos de incorporación-absorción y, en consecuencia, de biodisponibilidad. Entre estos cabe destacar (Holford, 1987):

1. El tiempo que el etanol permanece en el estómago no sólo produce un retraso en la absorción desde el intestino, sino que permite su metabolismo a través de los sistemas enzimáticos contenidos en este órgano. Esta latencia hacia el intestino se ve incrementada por factores tales como la presencia de comida sólida en el mismo. Por el contrario, está dilación se ve reducida por la gasificación de las bebidas alcohólicas o la administración concurrente de antagonistas de los receptores histaminérgicos $\mathrm{H} 2$ (muy utilizados en el tratamiento sintomático de úlceras estomacales). Estos factores delimitan la concentración máxima de etanol en sangre pero no parecen modificar el curso temporal del mismo.

2. Las diferencias genéticas en los enzimas capaces de metabolizar el etanol pueden producir importantes variaciones en la biodisponibilidad de esta sustancia. En este sentido el polimorfismo del enzima alcohol deshidrogenasa (ADH) puede producir importantes diferencias en los niveles de etanol en sangre. En este sentido, el menor nivel de expresión de este enzima en mujeres, propicia mayores concentraciones de etanol en éstas que en varones ante consumos idénticos. También existen diferencias raciales, constatándose una menor actividad de la $\mathrm{ADH}$ en la mucosa gástrica de los orientales respecto a los caucásicos.

3. El nivel de concentración de las diferentes bebidas alcohólicas también produce importantes diferencias en la velocidad de absorción. Así, existe una relación de $U$ invertida entre concentración del preparado etílico y dicha velocidad, alcanzando ésta su nivel máximo cuando la concentración de etanol se sitúa en torno a un $40 \%$.

4. El nivel de circulación sanguínea es inversamente proporcional a la máxima concentración de etanol en sangre que se obtiene. Así, por ejemplo, la administración de sustancias, como el propanolol, que aumentan esta circulación pueden producir cambios de hasta un $25 \%$ en dichas concentraciones séricas de etanol.

5. Pese a que históricamente ha existido cierta controversia al respecto, el momento del ciclo menstrual no parece poseer ninguna influencia en la farmacocinética del etanol.

6. El consumo de tabaco concurrente con el de etanol parece producir una reducción de la concentración máxima de etanol, posiblemente debido a que enlentece el tránsito del paso de etanol desde el estómago al intestino (Johnson et al., 1991). 


\subsection{Distribución del etanol.}

Como ya se ha comentado, el etanol, aún siendo una molécula anfipática, se disuelve mucho mejor en el agua que en los lípidos (esta relación es aproximadamente de 30/1), y por ello, su distribución es análoga a la del agua en el cuerpo (Gessner, 1993). La mayor solubilidad del etanol en el agua respecto a la que presenta en medios lipídicos propicia que se observen diferencias en la distribución del etanol entre dos individuos con diferente proporción de grasa corporal, aún cuando la cantidad ingerida de esta sustancia y su peso corporal sean idénticos.

Así, debido a las diferencias genéticas entre hombres y mujeres en la cantidad grasa, el volumen de distribución del etanol será diferente en cada caso $(0.7 \mathrm{~L} / \mathrm{kg}$ en hombres respecto a $0.6 \mathrm{~L} / \mathrm{kg}$ en mujeres). Este hecho, junto con la tendencia media de un menor peso corporal de las mujeres provoca mayores niveles de etanol en sangre en éstas ante un mismo consumo de etanol. De forma similar, el incremento en la grasa corporal que se observa con la edad en varones produce que ante una ingestión de la misma cantidad de etanol, las concentraciones séricas de etanol sean mayores en personas de mayor edad.

Por otra parte, el etanol cruza sin dificultad la barrera placentaria y la barrera hematoenecefálica. Con idéntica facilidad, el etanol accede a los pulmones desde el torrente sanguíneo y se vaporiza en el aire a una velocidad constante, siendo por ello posible determinar la concentración sérica de este alcohol desde los niveles contenidos en el aire exhalado, como ya se ha descrito.

\subsection{Eliminación del etanol.}

La mayor parte de la eliminación del etanol se produce por metabolismo (tal y como se describe en el apartado siguiente), pero existe un escaso porcentaje de etanol que es eliminado, sin sufrir transformación alguna, mediante su incorporación a la orina, las heces, el sudor y el aire exhalado. De hecho, para las dosis y concentraciones de etanol consumidas habitualmente, sólo el $1 \%$ de la eliminación está ligada a factores no-metabólicos.

Existe una gran variabilidad en las velocidades y tasas de eliminación de etanol entre diferentes sujetos, pero se suele considerar que la media de la población elimina entre 10 y $20 \mathrm{Mg}$. de etanol por cada $100 \mathrm{ml}$ de sangre y hora. En esta velocidad no parece que la edad o el sexo sean factores determinantes, pero sí parece serlo la asiduidad de los episodios de bebida, ya que conforme aumenta ésta aumenta también la capacidad metabólica y de eliminación del etanol.

Finalmente, existen otros factores que pueden alterar la eliminación del etanol. Éstos, brevemente presentados, son:

1. Factores genéticos, como la existencia de diferentes polimorfismos dependientes de la expresión diferencial de los alelos que codifican la síntesis de los enzimas capaces de degradar el etanol. Dependiendo del alelo presente, la contribución de cada sistema enzimático a la eliminación del etanol se verá comprometida.

2. El consumo de azúcares como la fructosa pueden incrementar la desaparición del etanol. Este efecto parece depender de cambios en la velocidad máxima de la $\mathrm{ADH}$, aunque sin modificación de su $\mathrm{Km}$. Este efecto de la fructosa se ha intentado utilizar como una forma de disminuir la intoxicación etílica en pacientes cuya vida pueda correr peligro por dicha causa, pero no parece ser lo suficientemente potente (Brown et al. 1972).

3. La capacidad metabólica de bebedores habituales parece ser mayor que la de personas con un menor contacto con esta sustancia. Esta diferencia parece depender de una inducción del MEOS en los primeros, como respuesta a la presencia crónica de sustrato.

4. El uso de contraceptivos orales reduce la eliminación del etanol hasta en un $20 \%$ 
(Jones y Jones, 1984). Otros fármacos (paracetamol, ácido acetilsalicílico, etc), productos industriales (PVC, acetona y otros solventes orgánicos, etc) y drogas (opiáceos, cocaína, etc) de abuso parecen ser capaces de interferir con el metabolismo del etanol, fundamentalmente porque actúan como competidores de los sistemas enzimáticos responsables de su degradación. Sin embargo, ya que muchas de estas sustancias afectan al MEOS más que a la ADH presentan un impacto leve o moderado sobre la desaparición de cantidades de etanol en el rango de consumo normalmente observado.

5. Los fumadores de tabaco (con un consumo superior a 20-25 cigarrillos por día) presentan una mayor velocidad de desaparición del etanol.

6. Se ha sugerido la existencia de un ritmo circadiano en la velocidad de desaparición del etanol. Sin embargo, en humanos, la existencia de dicho ritmo está aún por confirmar.

\section{METABOLISMO DEL ETANOL}

El etanol se metaboliza fundamentalmente por oxidación, transformándose en acetaldehido. En las situaciones de consumo oral, las más habituales, este proceso acontece principalmente en el hígado y se halla fundamentalmente mediado por la enzima alcohol deshidrogenasa (ADH) (alcohol: NAD-oxidorreductasa, EC 1.1.1.1) (Petersen et al., 1983). Esta enzima cataliza la conversión reversible de los alcoholes a sus correspondientes aldehidos y cetonas utilizando NAD (Nicotinamida-Adenina-Dinucleótido) como cofactor:

$$
\text { Alcohol }+\mathrm{NAD}=\text { Aldehido (Cetona) }+\mathrm{NADH}+\mathrm{H}^{+}
$$

Existen también otros dos sistemas enzimáticos hepáticos que posibilitan esta misma reacción y que adquieren relevancia ante niveles muy elevados de alcohol o alguna deficiencia en el sistema principal. Estos dos sistemas son el llamado sistema microsomal oxidativo del etanol (MEOS) y el mediado por el complejo catalasa-peróxido de hidrógeno (Compuesto I).

En un segundo paso el acetaldehido producido es metabolizado a acetato principalmente por la aldehido deshidrogenasa hepática (ALDH; EC 1.2.1.3).

Asimismo, existen indicios claros de la existencia de un metabolismo oxidativo extrahepático del etanol en diferentes órganos corporales tales como el corazón, el estómago (Salmela et al., 1996), los riñones (DeMaster et al., 1986) y el cerebro (Cohen et al., 1980). Este metabolismo está mediado por uno o más de los sistemas enzimáticos localizados en el hígado, aunque la predominancia entre ellos en cada tejido está aún en fase de estudio, así como lo está también, la significación funcional de dicho metabolismo.

No obstante, el acetaldehido no es el único metabolito que puede formarse después del consumo de etanol. Además del metabolismo oxidativo del etanol se ha descrito un metabolismo no oxidativo que da lugar a la formación de esteres etílicos de los ácidos grasos (Goodman y Deyking, 1963; Mogelson y Lange 1984).

\subsection{Sistemas enzimáticos implicados en el metabolismo hepático del etanol.}

\section{Alcohol Deshidrogenasa (ADH)}

En los seres humanos, pero también en roedores, la $\mathrm{ADH}$ es un sistema que implica varios genes y alelos que dan lugar a diferentes subtipos de enzimas. En humanos se han clonado, hasta el momento, siete genes diferentes para la ADH (Edenberg y Brown, 1992) (Kitson y Weiner, 1996; Lieber, 1997 para revisiones recientes). Cinco de estos genes (ADH1, 2, 3, 4 o 5) codifican diferentes subunidades de la ADH hepática $(\alpha, \beta, \gamma, \pi, \chi)$. La presencia de una $u$ otra subunidad produce diferentes isoenzimas. Los distintos isoenzimas se han agrupado en tres clases: ADH clase I (contiene las subunidades $(\alpha, \beta, \gamma)$, 
ADH clase II (subunidad $\pi$ ) y ADH clase III (subunidad $\chi$ ). Para las subunidades $\beta$ y $\gamma$ se ha descrito polimorfismo, de tal forma que la existencia en la ADH2 de diferentes alelos para la subunidad $\beta(\beta 1, \beta 2, \beta 3)$ y en la ADH3 alelos para la subunidad $\gamma(\gamma 1, \gamma 2, \gamma 3)$, produce diferencias en las propiedades cinéticas de cada isoenzima (Kitson y Weiner, 1996; Lieber, 1997).

Los valores de la $\mathrm{Km}$ para las diferentes clases del enzima (I, II, III) se encuentran en un rango entre $0.05 \mathrm{mM}$ para la $\mathrm{ADH} 2$ típica ( $\beta 1 \beta 1$ ) y $1 \mathrm{M}$ para la clase III $(\chi)$ que, por tanto, aparece como no saturable (Kitson y Weiner, 1996). No obstante, y debido a su baja afinidad por el sustrato, la clase III de ADH no parece participar en la oxidación del etanol, incluso aunque se alcanzen altas concentraciones en plasma (Lieber, 1997).

Mediante técnicas de hibridación con oligonucleótidos específicos para los distintos alelos, se ha podido demostrar la distribución no homogénea de dichos alelos en distintas poblaciones humanas. La presencia de la subunidad $\beta 1$ es muy común entre la población caucasiana; la subunidad $\beta 2$ se encuentra mayoritariamente en poblaciones orientales y la subunidad $\beta 3$ se ha descrito en algunas poblaciones africanas (Lieber, 1997). La isoenzima de la ADH2 que contiene la subunidad $\beta 2$ fue identificada como una ADH atípica por Von Wartburg et al. en 1965 y puede, si se compara con la ADH2 típica (sólo $\beta 1$ ), oxidar etanol más rápidamente. Por tanto, y transitoriamente al menos, los individuos con dicha isoforma del enzima acumularían mayores niveles de acetaldehido tras el consumo de etanol con las consecuencias tóxicas que serán descritas más adelante.

\section{Meos (P450 CYP2E1)}

Como ya se ha señalado en apartados anteriores, el enzima $\mathrm{ADH}$ no es el único sistema capaz de metabolizar etanol en el hígado. Éste, al ser un enzima de baja Km, se satura fácilmente. Parece, por ello, que en situaciones de consumo elevado o de inges- tión crónica, otros dos sistemas enzimáticos deben ser activados para que tenga lugar la eliminación hepática del etanol.

Uno de ellos es el MEOS (sistema microsomal de oxidación del etanol), localizado en el retículo endoplasmático de las células. Este sistema enzimático es miembro de la familia de los citocromos microsomales P450, y la denominación actual más extendida para este sistema es P450 CYP2E1, que corresponde a la proteína purificada. Es un enzima que presenta un alta $\mathrm{Km}$ (8-10 $\mathrm{mmol} / \mathrm{l})$, si se compara con la ADH . El citocromo 2E1 puede ser inducido por la administración crónica de alcohol en hígado (Lieber y DeCarli, 1968; 1970) y otros tejidos (Roberts et al., 1994; Upadhya et al., 2000); aunque se ha demostrado también su inducción con un tratamiento agudo de etanol (Koop, 1992). Esta inducción está asociada con una oxidación del alcohol en todos estos tejidos (Koop, 1992), y de este modo, parece estar ligada a la síntesis de acetaldehido. El 2E1 es, asimismo, inducido por otros compuestos tales como la acetona, isoniazida, imidazol, pirazol, 4-metilpirazol, algunos de los cuales también son sustratos para el enzima, y por tanto, metabolizados por él.

La función fisiológica del P450 2E1 está relacionada con la obtención de glucosa via metabolismo, en situaciones en las que estos niveles son bajos y los lípidos son la fuente energética fundamental (Song y Cederbaum, 1996). Sin embargo, su inducción puede llevar a hepatotoxicidad, debido a que muchos tóxicos potenciales requieren del metabolismo microsomal para ejercer sus efectos deletéreos sobre la célula.

El mecanismo por el cual el etanol induce este enzima sigue siendo, por el momento, una cuestión no totalmente resuelta. Los datos experimentales avalan una inducción postranscripcional mediante la estabilización de la proteína, al ser abolida la fase rápida de degradación de ésta (Roberts et al., 1994; Hu et al., 1995). No obstante, si el consumo de elevadas cantidades de alcohol se prolonga en el tiempo, y especialmente, si coincide con fases de ayuno, se ha observado una 
activación transcripcional del gen del CYP2E1 (Hu et al., 1995). Ambos mecanismos pudieran estar implicados en el metabolismo en pacientes alcohólicos, porque en dichos pacientes se ha observado un aumento de la proteína hepática $2 \mathrm{E} 1$ a la vez que en el ARNm (Takahasi et al., 1993).

Otra de las cuestiones sin resolver, se refiere a la contribución del MEOS al metabolismo general del etanol. Algunos autores (Thurman y Handler, 1989) han señalado que con una administración aguda de etanol, el MEOS es un sistema que contribuye en escasa medida a dicho metabolismo, tanto en presencia como en ausencia de $A D H$, cifrando dicha contribución entre un 3 y un $8 \%$ respectivamente. Sin embargo, cuando los datos se refieren a los niveles de eliminación de etanol tras un tratamiento crónico, estos valores alcanzan más del 22\% (Thurman y Handler, 1989; Song y Cederbaum, 1996).

\section{Catalasa}

La catalasa $\left(\mathrm{H}^{2} \mathrm{O}^{2}: \mathrm{H}^{2} \mathrm{O}^{2}\right.$ oxidorreductasa, EC 1.11.1.6; CAT) es un enzima tetramérico con un grupo hemo en cada subunidad. El gen de la catalasa humana ha sido localizado en el cromosoma 11 (Goth y Pay, 1996). Se encuentra en todos los organismos aeróbicos y todo indica que su función es degradar rápidamente peróxido de hidrógeno. La catalasa es uno de los más activos catalizadores producidos por la naturaleza. Es única entre las enzimas que degradan $\mathrm{H}^{2} \mathrm{O}^{2}$ porque lo hace de una manera muy eficiente energéticamente por ello se ha propuesto como sistema regulador de la homeostasis de peróxido de hidrógeno en la célula.

Dependiendo de la concentración de peróxido, ejerce una función dual. A bajas concentraciones actúa peroxidáticamente de modo que una variedad de donores de hidrógeno, como el etanol, el metanol o el ácido ascórbico, pueden ser oxidados. A altas concentraciones de substrato, la catalasa descompone el peróxido de hidrógeno rápidamente sir- viéndose de una reacción catalática en la cual el $\mathrm{H}^{2} \mathrm{O}^{2}$ actúa tanto como aceptor, como donor de moléculas de hidrógeno (Berkaloff et al., 1988).

Las pruebas espectrofotométricas y cinéticas sugieren que la catalasa utiliza un mecanismo de dos pasos en la reacción peroxidática y en la catalática. En el primer paso el hierro del grupo hemo de la catalasa interacciona con el peróxido de hidrógeno para formar peróxido de hidrógeno rico en hierro.

$$
\mathrm{CAT}-\mathrm{Fe}-\mathrm{OH}+\mathrm{H}^{2} \mathrm{O}^{2}=\mathrm{CAT}-\mathrm{Fe}-\mathrm{OOH}+\mathrm{H}^{2} \mathrm{O}
$$

Este peróxido de hierro intermediario (CATFe-OOH) es denominado Compuesto I, puede ser detectado in vitro e in vivo. A bajas concentraciones de $\mathrm{H}^{2} \mathrm{O}^{2}$, el compuesto I puede ser reducido peroxidáticamente por donores de hidrógeno como el etanol.

$$
\begin{array}{r}
\mathrm{CAT}-\mathrm{Fe}-\mathrm{OOH}+\mathrm{C}^{2} \mathrm{H}^{5} \mathrm{OH}=\mathrm{CAT}-\mathrm{Fe}-\mathrm{OH}+\mathrm{H}^{2} \mathrm{O}+\mathrm{CH}^{3} \mathrm{CHO} \\
\text { Etanol Acetaldehido }
\end{array}
$$

Parece ser, que en diferentes órganos de los mamíferos la catalasa funciona de esta manera. En órganos como el hígado, donde hay altas concentraciones de catalasa, se encuentran también bajos niveles de $\mathrm{H}^{2} \mathrm{O}^{2}$. Si la actividad de la catalasa se inhibe, las concentraciones de peróxido aumentan en el hígado (Yang y DePierre, 1998).

Las contribuciones de la catalasa al metabolismo hepático del etanol pudieran verse seriamente comprometidas (Lieber, 1997), ya que los niveles de peróxido de hidrógeno presentes en el organismo pudieran ser insuficientes para posibilitar el nivel de funcionamiento que algunos autores le atribuyen. No obstante, existen pruebas que indican que los niveles de peróxido de hidrógeno presentes en algunas mediciones in vitro pueden ser menores de los existentes in vivo lo que puede estar reduciendo la importancia percibida de la vía metabólica mediada por la catalasa. Así, la adición de ácidos grasos o albúmina (que elevan la cantidad de $\mathrm{H}^{2} \mathrm{O}^{2}$ ) a estas preparaciones, posibilita que este sistema devenga el principal responsable de la oxidación del etanol en ausencia de la ADH. De forma paralela, se encuentran datos que señalan cambios en el metabolismo hepático 
del etanol (independientes de la ADH) cuando los animales reciben una dieta rica en carbohidratos (Keegan y Batey, 1993). También se ha observado que a dosis superiores a 3 $\mathrm{g} / \mathrm{kg}$ de etanol, la inhibición de la catalasa por el AT (3-amino-1,2,4-triazole), un inhibidor del Compuesto I, produce un enlentecimiento de la eliminación del etanol, lo que hace suponer la participación de este enzima cuando las concentraciones de alcohol son elevadas.

\section{Metabolismo hepático del acetaldehído: La aldehido deshidrogenasa.}

El acetaldehido, producido por la oxidación del etanol a través de cualquiera de los sistemas enzimáticos antes descritos, es metabolizado en acetato por la aldehido deshidrogenasa hepática. La ALDH es un enzima tetramérico que oxida gran variedad de aldehidos alifáticos como el acetaldehido, además de otros aldehidos de tipo aromático. La ALDH mitocondrial de baja Km oxida el acetaldehido mediante la transferencia de hidrógeno al cofactor NAD y así forma ácido acético o acetato.

$\mathrm{CH}_{3} \mathrm{CHO}+\mathrm{NAD}^{+}+\mathrm{H}_{2} \mathrm{O}-\mathrm{CH}_{3} \mathrm{COOH}+\mathrm{NADH}+\mathrm{H}^{+}$

El acetaldehido puede ser también reducido a etanol por la $\mathrm{ADH}+\mathrm{NADH}$, pero ésta ha sido reconocida como una vía menor de eliminación del acetaldehido (Kitson y Weiner, 1996).

En los seres humanos, se han aislado 12 genes que codifican distintos tipos de ALDH (ALDH1-ALDH12) con secuencias de aminoácidos bien diferenciadas. Los loci para algunos de esos genes están en diferentes cromosomas $(9,11,12,17)$ (Kitson y Weiner, 1996). Sin embargo, las isoenzimas hepáticas son solamente dos, la ALDH1 citosólica y la ALDH2 mitocondrial; el resto se encuentra distribuido en otros tejidos (Kitson y Weiner, 1996). El acetaldehido se metaboliza fundamentalmente en la mitocondria, al contrario que el etanol, cuyo metabolismo hepático es esencialmente citosólico.

Sólo la ALDH2 mitocondrial tiene una variante genética ALDH2* 2 que ha sido descrita en humanos, para aproximadamente el $40 \%$ de los orientales y menos del $10 \%$ de
Ios caucasianos (Kitson y Weiner, 1996; Lieber, 1997). Esta isoforma del enzima es funcionalmente inactiva debido a la sustitución, en la posición 487, del aminoácido glutamato por lisina (Yoshida et al., 1984). Dicha sustitución origina una ALDH (2*2) con una altísima $\mathrm{Km}(7000 \mu \mathrm{M}$ comparada con $30 \mu \mathrm{M}$ para la ALDH2*1) y muy baja actividad específica (10\%) (Farres et al., 1994). Por tanto, en estos individuos la oxidación del acetaldehido es muy deficiente, produciéndose acumulaciones de éste, después, incluso del consumo moderado de alcohol. La acumulación de acetaldehído origina fuertes efectos tóxicos y da lugar al síndrome de sensibilidad al alcohol (flushing response) que será analizado más adelante. Dicho síndrome puede también ser observado en humanos si se expone a los sujetos a inhibidores del enzima (Eriksson, 2001). Algunos de estos compuestos, especialmente, el disulfirán y la carbamida de calcio, han constituido durante muchos años la terapia antialcóholica fundamental, basada, teóricamente, en la protección contra el consumo de alcohol que la acumulación de acetaldehido debería producir en aquellos sujetos tratados con inhibidores de la ALDH. Otros inhibidores, son solventes que, de ser inhalados, pueden aumentar la sensibilidad de los individuos al etanol mediante el mismo mecanismo de acumulación de acetaldehido.

\subsection{Metabolismo extrahepático del eta- nol.}

\section{Metabolismo cerebral de etanol.}

Como hemos expuesto en apartados anteriores, la oxidación del etanol en humanos y otros animales se da en dos etapas y acontece principalmente en el hígado. A pesar de ello, existe la posibilidad de que, junto al periférico, exista un metabolismo cerebral del etanol. Esta posibilidad queda sustentada por la demostración de la existencia, en el SNC, de diferentes sistemas enzimáticos capaces de metabolizar el etanol.

En el caso del cerebro el mapa enzimático es menos conocido que en el hígado y parece 
ser un tanto diferente. De hecho, la importancia relativa de los sistemas enzimáticos parece variar notablemente en el cerebro en relación al hígado. Así, la ADH clase I, que en el hígado es el principal oxidante del etanol a concentraciones bajas y moderadas, posee una muy limitada actuación en el SNC (Raskin y Sokoloff, 1972). Hasta el momento, no se ha podido demostrar la presencia de la isoforma I de $\mathrm{ADH}$ en cerebro (Lands, 1998 para una reciente revisión). Fundamentalmente, en el cerebro de humanos y también en el de ratones, la isoforma más abundante de esta enzima es la clase III (Rout, 1992). Sin embargo, esta isoforma, como ya hemos señalado anteriormente, tiene baja afinidad por el etanol y difícilmente es activada por éste; ya que aun en severas intoxicaciones etílicas, no se alcanzan las concentraciones necesarias para que su contribución sea relevante (Gill et al., 1992).

También se ha descrito la presencia de citocromos pertenecientes al complejo enzimático MEOS, y en concreto, se ha demostrado que el CYP450 cerebral es inducido por el etanol como ocurría en el hígado (Lands, 1998; Upadhya et al., 2000). La presencia e inducción de este enzima microsomal en el cerebro reviste mucha importancia. Al existir la evidencia de que el 2E1 hepático es normalmente inducido por los sustratos a los que metaboliza, su inducción cerebral es una prueba indirecta para la hipótesis de la oxidación cerebral del etanol en acetaldehido. Se sabe que la distribución cerebral del CYP2E1 en humanos no es uniforme (Upadhya et al., 2000); concentrándose sobre todo en neuronas del cortex cerebral, células de Purkinje y granulares del cerebelo, el giro dentado y el hipocampo. De esta forma, aunque solamente cantidades muy pequeñas de alcohol sean oxidadas en el cerebro, la generación local de acetaldehído puede tener importantes consecuencias funcionales. Por ejemplo, esta inducción ha sido asociada con la aceleración de la lipidoperoxidación y posiblemente con los efectos tóxicos del etanol y la alteración de las membranas neurales (Montoliu et al., 1994).

Finalmente, existe un gran número de pruebas de que el sistema catalasa-peróxido de hidrógeno se halla presente y activo en el SNC (Smith et al., 1997; Zimatkin et al., 1998). Algunas investigaciones han presentado pruebas indirectas de la oxidación de etanol a acetaldehido en el cerebro de rata, vía el sistema enzimático catalasa+ peróxido de hidrógeno. Así por ejemplo, la inhibición irreversible del enzima con carbamida de calcio o 3-amino1,2,4-triazole puede ser prevenida por la administración previa de etanol a homogeneizados cerebrales (Cohen et al., 1980; Aragon et al. 1991). Esta protección de la inhibición del enzima por el etanol implica que en el tejido neural el etanol es capaz de unirse al enzima e impedir la acción de los inhibidores irreversibles, y por tanto, que el tejido neural tiene capacidad para oxidar etanol.

Estudios inmunohistoquímicos (Moreno et al., 1995) han puesto de relieve que la catalasa se sitúa fundamentalmente en los cuerpos de neuronas catecolaminérgicas del troncoencéfalo y también en ciertos tipos de glía de las mencionadas áreas, por tanto el número total de células neurales con alta concentración de catalasa (a los mismos niveles que en los hepatocitos) es muy pequeña en relación al total del cerebro. Esto explicaría los bajos niveles de actividad detectados en homogeneizados cerebrales de rata (Aragon et al., 1992; Gill et al., 1992). Por otro lado, la localización de las neuronas que contienen alta densidad de catalasa contrasta notablemente con localizaciones previamente realizadas para la ALDH (Zimatkin y Deitrich, 1995). Sin embargo, tomados en su conjunto, estos datos sugieren que aunque la cantidad total de acetaldehído que pueda producirse en el encéfalo a través de la catalasa sea pequeña, existe la posibilidad de que se produzcan acumulaciones de acetaldehido suficientes para provocar cambios en la fisiología y la actividad de determinados grupos neuronales.

\section{Metabolismo oxidativo del etanol en otros tejidos.}

Los tejidos de otros órganos corporales tales como el riñón, el corazón o el estómago también presentan uno o más de los siste- 
mas enzimáticos a los que nos hemos referido, y por tanto, son capaces, de oxidar etanol a acetaldehido.

A este respecto, el metabolismo más estudiado ha sido el digestivo. En el estómago humano se han descrito tres clases de ADH: ADH clase I, ADH clase III y ADH clase IV, que parece casi exclusiva para este tejido y que no se encuentra en el hígado (Kitson y Weiner, 1996; Lieber 1997). La mayoría de la oxidación gástrica del etanol tiene lugar en la mucosa mediante la ADH clase I (ADH3) y IV. La ADH3 está constituída por subunidades $\gamma$ que presentan polimorfismo ( $\left.\gamma 1 \gamma^{2}\right)$ y propiedades cinéticas diferentes dependiendo de la subunidad. La ADH IV humana exhibe una alta $\mathrm{Km}$ para el etanol (37mM) y mucha actividad enzimática, lo que hace pensar en una importante función protectora contra la penetración de alcoholes externos en el organismo. Se ha demostrado, recientemente, que puede haber metabolismo microbial del etanol en aquellos individuos colonizados por la bacteria Helicobacter Pylori, ya que dicha bacteria tiene ADH (Kitson y Weiner, 1996).

Aunque también se ha observado la presencia de catalasa en el estómago, su contribución al metabolismo del etanol no está clara, ya que dicho metabolismo gástrico puede ser bloqueado con inhibidores del ADH I y del ADH IV, pero no con azida sodica, un inhibidor competitivo del enzima catalasa (Lieber, 1997).

El metabolismo gástrico pudiera disminuir la cantidad de alcohol que penetra en torrente circulatorio y actuar así, como un metabolismo de primer paso (Lieber, 1997). No obstante, este concepto ha sido controvertido y otros autores han señalado que el efecto de primer paso se llevaría a cabo en el hígado y no en el estómago (Levitt y Levitt 1994).

\subsection{Metabolismo no oxidativo del etanol}

Además del metabolismo oxidativo enzimático, también existen vías de metabolismo de etanol no oxidativas que se producen a través de la formación de esteres etílicos de los áci- dos grasos (Goodman y Deyking, 1963; Mogelson y Lange, 1984) y fosfatidiletanol (Zimatkin y Deitrich, 1995) .

Los esteres etílicos son metabolitos no oxidativos del etanol que se pueden formar in vivo mediante una reacción catalizada por el enzima etil ester sintetasa (Mogelson y Lange, 1984). Se describió por primera vez en el músculo cardiaco de conejos (Mogelson y Lange, 1984), pero posteriormente se ha demostrado que en otros tejidos, incluido el hígado, se pueden formar este tipo de compuestos con la exposición al alcohol (Laposata y Lang, 1986). Los efectos fisiológicos de la formación de esteres etílicos consisten en la afectación de la capacidad oxidativa de la mitocondria, aunque también se ha descrito su capacidad para desordenar las membranas celulares. Estos metabolitos paracen tener una especial relevancia para el daño tisular cerebral originado por el consumo crónico de cantidades abundantes de etanol.

El fosfatidiletanol es sintetizado por la reacción del etanol con la fosfatidilcolina catalizada por el enzima fosfolipasa D (Wrighton et al., 1983). La formación de este compuesto se ha demostrado en células sanguíneas humanas y cerebro de rata (Zimatkin y Deitrich, 1995). Ya que se ha observado que la formación de este compuesto es mayor en alcohólicos que en sujetos normales, se ha sugerido que la formación de fosfatidiletanol pudiera considerarse como un marcador de la propensión al alcoholismo (Wrighton et al., 1983). Actualmente, se desconocen las consecuencias funcionales de la formación de fosfatidiletanol, no obstante, se ha demostrado que dicha formación aumenta la tolerancia de la membrana celular a los efectos desorganizadores del etanol (Omodeo-Sale et al., 1991).

\section{EL PAPEL DEL ACETALDEHIDO.}

Como hemos visto, el etanol se metaboliza fundamentalmente por oxidación enzimática, transformándose en acetaldehído. 
Tradicionalmente, el acetaldehído acumulado en el organismo ha sido implicado en los efectos aversivos que produce el etanol (Chao, 1995). De este postulado se derivan la mayoría de las terapias farmacológicas utilizadas para combatir el alcoholismo, que tratan de impedir el metabolismo hepático del acetaldehído administrando inhibidores de la ALDH como el disulfirán y la cianamida.

En humanos el acetaldehído se encuentra en niveles elevados durante la intoxicación al etanol. Este fenómeno causa muy diferentes efectos que en general son conocidos bajo el concepto "sensibilidad al alcohol" e incluyen: vasodilatación asociada a incrementos en temperatura cutánea, efectos subjetivos de calor y "flushing" facial, incrementa la tasa cardiaca y respiratoria, disminuye la presión sanguínea, produce sequedad de la mucosa bucal y de la garganta hecho que va asociado con broncoconstricción y reacciones alérgicas, nauseas y dolores de cabeza.

Las pruebas aportadas vienen de observaciones sobre los efectos de drogas que inhiben la ALDH y que, por lo tanto, producen una acumulación de acetaldehído en el cuerpo. Algunas de estas drogas son: Disulfiram (Antabuse), Coprine, Cianamida (calciumcarbamida o Temposil), Clorpropamida, Moxalactam y Nitrefazole. La mayoría de esta sensibilidad al alcohol esta claro que es mediada por el acetaldehído porque ha sido bloqueada cuando se coadministran inhibidores de la $\mathrm{ADH}$ como el 4-metilpirazole junto a los inhibidores de la ALDH como el Disulfiram o la Cianamida (Kupari et al., 1983). Esto también ha sido observado si se bloquea la $\mathrm{ADH}$ a individuos que poseen el alelo ALDH2*2 (Inoue et al., 1984). Es conocido el hecho de que existe un amplio sector de la población asiática que manifiesta sensibilidad al alcohol. Esto ha demostrado correlacionar con el polimorfismo de la ADH la ALDH y con niveles elevados de acetaldehído.

Nauseas y dolores de cabeza son síntomas típicos de la sensibilidad al alcohol producidos en tratamientos farmacológicos que inhiben la ALDH o en individuos con ALDH2* 2 .
Esto vincula el acetaldehído con los efectos de la resaca.

Así mismo, la contribución del acetaldehído a las acciones patológicas crónicas del etanol ha sido claramente vinculada a diferentes formas de cáncer en el tracto digestivo, en el de garganta y en la cirrosis hepática. Junto a esto el acetaldehído puede estar jugando un papel en el desarrollo de otras patologías como el daño cerebral, cardiopatías, pancreatitis y en el síndrome alcohólico fetal (Eriksson, 2001).

En cuanto a las acciones agudas, se ha asumido que la respuesta de flushing está asociada a efectos aversivos y que por ello el flushing resulta un factor protector contra la intoxicación y la adicción al alcohol. Esta asunción no es clara dado que respuestas de flushing aparecen al mismo tiempo que los sentimientos subjetivos de euforia que por lo tanto pueden conducir a un reforzamiento positivo de la conducta de ingesta de alcohol. Por ello, ha sido sugerido que las acciones del acetaldehído durante la intoxicación etílica son de naturaleza dual: acciones protectoras y promotoras de una posterior ingesta de alcohol (Eriksson, 2001)

Junto a los efectos tóxicos del acetaldehido, cada vez va apareciendo un mayor corpus de trabajos encaminados a demostrar que este metabolito del etanol es también responsable de algunos de los efectos psicofarmacológicos que se le atribuyen al propio etanol (Lindros, 1978; Aragon, et al., 1986; Bergamaschi et al., 1988; Chao, 1995; Smith et al., 1997; Zimatkin y Deitrich, 1997).

En los últimos años se han descrito algunos efectos derivados de la exposición del tejido cerebral al acetaldehído, in vitro (Kuriyama et al., 1987; Poldrugo y Snead, 1985) e in vivo (Barbaccia et al., 1982) que refuerzan la idea de que éste producto pudiera mediar algunos de los efectos psicofarmacológicos del etanol, en tanto que vinculan esta sustancia a efectos y estructuras neurales implicadas en el mecanismo de acción de otras drogas de abuso (Pastoric et al., 1994; Reddy y Sarkar, 1993; Reddy et al., 1995). 
Se ha demostrado la capacidad del acetaldehido para promover diferentes efectos en los sistemas clásicos de neurotransmisión, así como, en los mediados por neuropéptidos. Así, en estudios de cultivos de neuronas se han constatado cambios en las tasas de ligamiento de diferentes subtipos de receptores GABAérgicos, NMDA y acetilcolina (Kuriyama et al., 1987).

Por otra parte, hace más de dos décadas que se demostró la capacidad del acetaldehído para promover la liberación de noradrenalina en terminales del sistema nervioso periférico (Walsh, 1971) y en el SNC (Thadani y Truitt, 1977). Resultados similares a los referidos para la noradrenalina, se han constado para la serotonina y la dopamina (Ortiz et al., 1974). Respecto a esta última, se ha observado que el acetaldehído mimetiza, aunque con mayor velocidad, el incremento de DOPAC inducido por etanol en el estriado (Barbaccia et al., 1982). Hay evidencia de que el acetaldehído central puede inducir la liberación de catecolaminas (Truitt y Walsh, 1971). También hay datos que indican que la actividad de la enzima ALDH correlaciona positivamente con la actividad de la MAO y con otras medidas de actividad dopaminérgica (Zimatkin, 1991). En humanos, ha sido demostrado un vínculo entre niveles elevados de acetaldehído y catecolaminas (epinefrina y norepinefrina) en individuos asiáticos con respuesta de flushing durante la intoxicación alcohólica (Mizoi et al., 1983). Resultados similares se han encontrado en individuos de raza blanca tratados con inhibidores de la ALDH.

Respecto a los neuropéptidos, se ha demostrado que el acetaldehído es capaz de promover la liberación de $\beta$-endorfinas en cultivos celulares hipotalámicos (Pastoric et al., 1994). El flushing y la inhibición de la ALDH también han sido asociados con la liberación de péptidos. A su vez, se ha observado que la naloxona inhibe el flushing producido por la clorpropamida (Eriksson, 2001). Este dato resulta aun de mayor interés por cuanto diferentes autores han intentado poner en relación el reforzamiento y la recompensa de diferentes sustancias de abuso (entre ellas el alcohol/acetaldehido), con las $\beta$-endorfinas (Gianoulakis et al., 1996), así como con otros péptidos del sistema de opiáceos endógenos (Terenius, 1996).

La propuesta de que el acetaldehído pueda estar implicado en las reacciones de euforia, supone la posibilidad de que sea el acetaldehído, propiamente, el que esté promoviendo el consumo de alcohol. En estudios con animales, las pruebas más directas de la implicación del acetaldehído en los efectos reforzantes del etanol son las aportadas por paradigmas en que se permite a los sujetos la autoadministración de acetaldehído. Así, se ha constatado que los animales aprenden a manipular una palanca para autoadministrarse acetaldehído periféricamente (IV o IP) (Takayama y Ueno, 1985; Myers et al., 1984a,b) o incluso en el encéfalo (ICV o en el ATV) (Brown et al., 1979; 1980; Rodd-Henricks et al., 2000). Asimismo, la preferencia por el etanol y su consumo se incrementan tras la administración crónica ICV de acetaldehído (Myers y Veale, 1969). Además, tanto ICV como IP el acetaldehído es capaz de producir preferencia de lugar (Smith et al., 1984; Quetermont y De Witte, 2001).

En humanos, los estudios de consumo de alcohol muestran resultados contradictorios. Por un lado, el polimorfismo genético de los enzimas $A D H$ y $A L D H$ ha sido relacionado con la protección contra el alcoholismo, así como, con una mayor susceptibilidad a los efectos tóxicos del consumo de alcohol. Por ejemplo, los individuos con genotipos $\mathrm{ADH}_{2}{ }^{*} 2$ (con una subunidad $\beta 2$ ) y $\mathrm{ALDH} 2 * 2$ beben menos alcohol que los genotipos con isoenzimas normales. Sin embargo, aquellos que si consumen alcohol presentan una mayor propensión a desarrollar trastornos hepáticos (Yamauchi et al., 1995).

En contraste el acetaldehido y la respuesta de flushing ha sido asociada en individuos asiáticos (con ALDH2*2) con sensación de euforia (Mizoi et al., 1983) y se han descrito casos de dependencia al alcohol entre estos sujetos (Higuchi et al., 1994). Junto a esto, también se dan numerosos casos de individuos que expresamente buscan coadminis- 
trarse antabuse o cianamida con alcohol (Peachey et al., 1980). En poblaciones caucasianas se ha demostrado una asociación entre niveles elevados de acetaldehido y respuesta de flushing en individuos con antecedentes familiares de alcoholismo (Schuckit y Duby, 1982).

No obstante, existen numerosas reticencias a aceptar la hipótesis del acetaldehído como agente responsable de algunos efectos conductuales del etanol, debido a los problemas teóricos que se plantean. El acetaldehído derivado del metabolismo periférico del etanol es difícilmente detectado en la sangre tras un consumo normal y el que se escapa del metabolismo hepático, penetra con dificultad de la sangre al cerebro debido a la presencia en la barrera hematoencefálica de una barrera metabólica presentada por la ALDH (Zimatkin, 1991; Hunt, 1996). Se necesitan altos niveles de acetaldehído en la sangre, incluso mayores de los encontrados tras un consumo muy elevado, para poder detectarlo en el fluido cerebroespinal o en tejido nervioso (Tabakoff et al., 1976; Deitrich, 1987). A esta cuestión se le ha tratado de dar respuesta desde el planteamiento del metabolismo del etanol en el propio SNC. Es decir, el acetaldehído se formaría en el propio SNC a partir del etanol consumido por el organismo que alcanzase dicho sistema.

Esta hipótesis ha sido defendida por diferentes autores a lo largo de las tres últimas décadas (Amit et al.; 1985; 1986; 1989; Lindros, 1978; Myers et al., 1982) aunque para ello era necesario la demostración de una ruta metabólica viable en el mismo sistema nervioso central (Aragon et al., 1991; Gill et al., 1992). Este acetaldehído producido por la catalasa mediaría en los efectos reforzantes del etanol a través de su interacción con los sistemas de neurotransmisión implicados directamente en las conductas motivadas.

En este sentido, se han realizado diferentes propuestas acerca de cómo el acetaldehído puede generar estos efectos en el SNC. Así, el acetaldehído, como el etanol, parece capaz de intercalarse en las membranas plasmáticas de diferentes tipos de células (Kenney, 1980) y producir efectos localizados sobre ciertas estructuras de la membrana plasmática, fundamentalmente proteicas (Shiohara et al., 1986).

Asimismo, y también como decíamos al hablar del alcohol, la simplicidad estructural del acetaldehído parece descartar una relación de estereoespecificidad directa entre éste y algún receptor neural. Sin embargo, ésta pudiera producirse si el acetaldehído formara algún compuesto de mayor complejidad estructural. En este sentido, parece claro que el acetaldehido es una molécula mucho más reactiva que el etanol, debido fundamentalmente a la presencia de un grupo carbonilo que le permite interaccionar con una gran variedad de grupos nucleofílicos, especialmente si poseen algún grupo amino libre. Así, mediante este tipo de reacciones, el acetaldehído forma aductos que pueden ser inestables o estables. Respecto a los primeros, se ha demostrado que son especialmente frecuentes con grupos $-\mathrm{NH}^{2}$, $-\mathrm{SH}$, guanido- e imidazol- de las proteínas (Lumeng y Lin, 1992).

De este modo, el acetaldehído, incluso a bajas concentraciones, es capaz de formar aductos con lípidos, ácidos nucleicos y proteínas (Jennet et al., 1989). En el caso de los aductos formados con proteínas endógenas (albúmina, hemoglobina, etc), el acetaldehído presenta una especial afinidad por los grupos lisina de éstas, sin que se haya podido concluir el motivo exacto de la misma.

Este tipo de compuestos sí presenta una estructura más compleja que posibilitaría la estereoespecificidad con algún receptor neural. En este sentido, se ha documentado la posibilidad de que el acetaldehído forme, in vitro pero en concentraciones similares a las producidas en el metabolismo del etanol, aductos complejos mediante su interacción con substratos como las catecolaminas; dopamina y noradrenalina (Nuñez-Vergara et al., 1991). Así, se ha podido demostrar que como producto de estas reacciones de condensación entre acetaldehído y catecolaminas se generan una serie de compuestos conocidos genéricamente como tetrahidroisoquinolinas (TIQs). Por otra parte, cuando estas mismas interacciones se producen con 
metabolitos serotonérgicos se formarían otras macromoléculas conocidas como tetrahidro- $\beta$-carbolinas (THBCs) (Deitrich y Erwin, 1984).

En este sentido, existen diferentes informes que parecen señalar que determinados regímenes de administración ICV de algunos de estas tetrahidroisoquinolinas (Myers et al, 1982) o tetrahidro- $\beta$-carbolinas (Rommelspacher et al., 1987) pueden incrementar la preferencia por el etanol en ratas expuestas a situaciones de libre elección. No obstante otros autores presentan clara evidencia de lo contrario (Brown et al., 1980).

De forma paralela, el salsolinol (posiblemente el TIQ más estudiado) ha demostrado poseer efectos bifásicos dependientes de dosis sobre la actividad locomotora de ratones, pudiendo llegar a generar pérdida del reflejo de enderezamiento. Este estrecho paralelismo con los efectos del alcohol, se ve nuevamente reafirmado al constatarse que esta sustancia posee efectos diferenciales en dos estirpes seleccionadas por su respuesta a los efectos hipnóticos del etanol (short /long sleep) sin alterar otros que supuestamente no están mediados por el acetaldehído, como la hipotermia (Smolen y Collins, 1984). Estos datos experimentales son interesantes a la luz de resultados en humanos donde niveles elevados de salsonilol han sido detectados en orina de sujetos alcohólicos.

Así, respecto a los TIQs, se ha sugerido que pudieran actuar como inhibidores competitivos de determinadas enzimas implicadas en la síntesis de las catecolaminas, como el COMT, la MAO o la tirosín-hidroxilasa. No obstante las diferencias entre el umbral de saturación de las enzimas y las concentraciones predecibles de los TIQs, hacen muy improbable que este mecanismo tenga alguna relevancia in vivo. Una segunda posibilidad señala que algunos TIQs, especialmente la tetrahidropapaverolina (THP), puede ser un importante precursor de diferentes compuestos con capacidad para actuar sobre el sistema de opiáceos endógenos. Sin embargo, la afinidad de los TIO por estos receptores parece ser sólo un $50 \%$ del exhibido por agonistas opiá- ceos propiamente dichos. Finalmente, otra opción que se ha barajado es que las tetrahidroisoquinolinas actúen como falsos neurotransmisores en los diferentes sistemas catecolaminérgicos (Deitrich y Erwin, 1984).

\section{INTERACCIÓN DEL METABOLISMO DEL ETANOL CON OTRAS DROGAS Y NUTRIENTES}

Como ya ha quedado detalladamente explicado en los apartados anteriores, el metabolismo del alcohol se efectúa principalmente en el hígado por mediación del enzima alcohol deshidrogenasa. No obstante, a concentraciones saturantes de etanol para el complejo NAD-ADH, otros sistemas como MEOS y catalasa juegan un papel significativo y contribuyen en su oxidación a acetaldehido. La influencia del metabolismo del etanol en otras sustancias puede ser debida, por tanto, a una interacción directa de estas sustancias con las vías enzimáticas enumeradas o a cambios indirectos resultantes del metabolismo del etanol, como por ejemplo el estado redox de la célula que acontece siguiendo a la oxidación hepática del etanol (Lieber, 1994; Nordmann, 1994).

En este sentido, el sistema enzimático MEOS es de particular interés. Este complejo contiene como enzima fundamental al citocromo P-450 2E1 que pertenece, como ya se vió, a una numerosa familia de proteínas con propiedades catalíticas conocidas, los citocromos CYP-450. Estos enzimas son los más importantes catalizadores implicados en la biotransformación de sustancias xenobióticas como drogas, pesticidas, carcinógenos y productos naturales. Esta familia de citocromos, también tiene un papel muy significativo en el metabolismo de endobióticos, como esteroides o vitaminas liposolubles. La regulación individual de estos enzimas es muy compleja. Hay ejemplos de inducción y de inhibición o estimulación directa por el sustrato que esta siendo metabolizado. Por tanto, la presencia previa de un determinado sustrato 
puede afectar el metabolismo de un sustrato posterior. El consumo crónico o excesivo de etanol produce, como ya explicamos, una inducción significativa del P-450 2E1 y otros citocromos P-450 en las células hepáticas (Lieber, 1997). El mecanismo responsable de dicha inducción no se conoce suficientemente. No obstante, se ha propuesto que la presencia de etanol en la célula retrasaría la degradación de esta proteína en los hepatocitos por las proteasas, aumentando así, la vida media de este componente microsomal. Este aumento de la actividad observada, siguiendo el consumo de alcohol, pudiera ser el resultado de la ruptura del equilibrio entre degradación y síntesis de CYP2E1 en las células hepáticas. De ser así, el consumo crónico de alcohol puede producir como consecuencia un metabolismo acelerado de sustancias que son substratos para estos enzimas (Goldberg et al., 1989). El efecto contrario, es decir, la disminución de la tasa de metabolismo de un substrato, podría ocurrir con una dosis aguda de alcohol. Este efecto se debería, en parte, a la habilidad del etanol para enlazarse con los isoenzimas CYP450 y así, competir con el metabolismo de otras sustancias que son substratos para este sistema enzimático (Hoensch, 1987).

Como prueba de lo anteriormente expuesto, se ha demostrado que numerosos xenobióticos, entre los que se encuentran alcoholes y cetonas, nitrosaminas, compuestos aromáticos, y alcanos halogenados y éteres, presentan un metabolismo microsomal acelerado siguiendo una exposición crónica de alcohol, en animales y en el hombre (Koop y Coon, 1986; Nuñez-Vergara et al., 1991; Djordjevic et al. 1998). Por ejemplo, hay gran cantidad de estudios clínicos que demuestran que la conversión de acetaminofeno (paracetamol) a sus metabolitos activos se acelera con el consumo crónico de alcohol, causando consecuentemente, problemas hepáticos en sujetos expuestos a una dosis moderada, meramente terapéutica de acetaminofeno (McClain et al., 1980). Paradójicamente, la administración aguda de alcohol puede proteger al hígado de una sobredosis de esta compuesto al inhibirse su conversión metabólica en metabolitos activos (Banda y Quart, 1982).

También se han descrito numerosos ejemplos de interacción del metabolismo del etanol con sustancias endobióticas. El Retinol es el principal compuesto con una función de vitamina A. Como el etanol, el retinol es un alcohol y, al menos, in vitro, y posiblemente in vivo, puede ser convertido en su correspondiente aldehído en reacciones enzimáticas catalizadas por varios isoenzimas de la alcohol deshidrogenasa citosólica, así como, por otras enzimas deshidrogenasas (Duester, 1998). Además, el metabolismo del retinol también tiene lugar en microsomas hepáticos que implican al citocromo P450 que, a su vez, está implicado en el metabolismo de diversas sustancias entre las que se encuentra también el etanol. Por tanto, ambas sustancias compiten por los mismos sistemas enzimáticos $\mathrm{y}$, no es sorprendente, que ocurran interacciones importantes entre ambas. De este modo, la capacidad de estos sistemas para oxidar el retinol se ve comprometida con la presencia en el organismo de concentraciones altas o intoxicantes de etanol. Sin embargo, con el consumo crónico o excesivo de etanol se favorece el metabolismo del retinol, ya que el etanol induce enzimas que degradan ambas sustancias, como el citocromo P450 microsomal hepático o la retinol deshidrogenasa citosólica, enzima similar o idéntica a la alcohol deshidrogenasa. Consecuentemente, en sujetos alcoholizados, éste metabolismo acelerado del retinol es una de las causas que produce una deficiencia de vitamina A. Niveles bajos de esta vitamina en el hígado están asociados con la fibrogénesis y la activación proliferativa de células en el hígado, ambas observadas en algunos pacientes alcohólicos (Leo y Lieber, 1999).

No obstante, nos gustaría hacer algunas consideraciones como comentario final a este apartado. La interacción del metabolismo del etanol con fármacos y otras drogas es un área insuficientemente estudiada, a pesar del aumento del uso de estos productos, tanto clínicamente como de forma recreativa. 
Además, aunque el metabolismo farmacológico, y el del etanol concretamente, se realiza mayoritariamente en el hígado, no se debe olvidar que otros tejidos incluyendo SNC pueden tener un papel muy importante en la interacción entre el alcohol y los fármacos.

\section{REFERENCIAS BIBLIOGRÁFICAS}

(1) Bogen E. The human toxicology of alcohol. Chapter IV in Alcohol and Man. Emerson, $\mathrm{H}$. (Ed.). The Macmillan company, New York, 1932.

(2) Holford HG. Clinical Pharmacokinetics of ethanol. Clin Pharmacokinetics 1987; 13:273- 92*.

(3) Johnson RD, Horowitz, Maddox AF, Wishart JM, Shearman DJC. Cigarette smoking and rate of gastric emptying: effect on alcohol absortion. British Medical Journal 1991; 302: 20.

(4) Gessner PK. Alcoholes. En Smith CM y Reynard AM (eds). Farmacología. Editorial Panamericana, Montevideo, 1993.

(5) Brown SS, Forrest JAH, Roscoe AP. A controlled trial of fructose in the treatment of acute alcoholic intoxication. Lancet 1972; 2: 898-00.

(6) Jones MK, Jones BM. Ethanol metabolism in women taking oral contraceptives. Alcohol Clin Exp Res 1984; 8: 24-8.

(7) Petersen DR, Erwin VG, Deitrich RA. Brain acetaldehyde metabolism during ethanol consumption. Res. Monographics 1983; 9: 93-9.

(8) Salmela KS, Kaihovaara P, Salaspuro M, Roine $\mathrm{RP}$. Role of catalase in rat gastric mucosal ethanol metabolism in vitro. Alcohol Clin Exp Res 1996; 20:1011-15.

(9) DeMaster EG, Redfern B, Shirota FN, Nagasawa HT. Differential inhibition of rat tissue catalase by cyanamide. Biochem Pharmacol 1986; 35: $2081-85$.

(10) Cohen G, Sinet PM, Heikkila R. Ethanol oxidation by rat brain in vivo. Alcohol Clin Exp Res 1980; 4: 366-70.

(11) Goodman DW, Deyking D. Fatty acid ethyl ester formation during ethanol metabolism in vivo. Proc Soc Exp Biol 1963; 113: 65-7.

(12) Mogelson S, Lange LG. Nonoxidative ethanol metabolism in rabbit myocardium purification to homogeneity of fatty acid ethyl ester synthase. Biochemistry 1984; 23: 4075-81.
(13) Edenberg HJ, Brown CJ. Regulation of human alcohol dehydrogenase genes. Pharmacogenetics 1992; 2: 185-96.

(14) Kitson KE, Weiner H. Ethanol and acetaldehyde metabolism: Past, present and future. Alcohol Clin Exp Res 1996; 20: 82A-2A**.

(15) Lieber CS Ethanol metabolism, cirrhosis and alcoholism. Clin Chim Acta 1997; 257: 59$4^{* *}$.

(16) Von Wartburg JP, Papenber G J, Aebi H An atypical human alcohol dehydrogenase. Can J J Biochem 1965; 43: 889-98.

(17) Lieber CS, DeCarli LM. Ethanol oxidation by hepatic microsomes: Adaptative increase after ethanol feeding. Science 1968; 162: 917-18.

(18) Lieber CS, DeCarli LM. Hepatic microsomal ethanol-oxidating system. In vitro characteristics and adaptative properties in vivo. J Biol Chem 1970; 245: 2505-12.

(19) Roberts BJ, Shoaf SE, Jeong K-S, Song BJ. Induction of CYP2E1 in liver, kidney, brain and intestine during chronic ethanol administration and withdrawal: Evidence that CYP 2E1 possesses a rapid phase half-life of 6 hours or less. Biochem Biophis Res Com 1994; 205:1064-71.

(20) Upadhya S, Tirumalai S, Boyd MR, Mori T, Ravindranath V. Cytocrome P4502E (CYP2E1) in brain: Constitutive expression, induction by ethanol and localization by fluorescence in situ hybridation. Arch Biochem Biophys 2000; 373: 23-4.

(21) Koop DR Oxidative and reductive metabolism by cytocrome P450 2E1. FASEB J 1992; 6: 724-30.

(22) Song BJ, Cederbaum Al. Ethanol inducible cytochrome P450 (CYP2E1): Biochemistry, molecular biology and clinical relevance: 1996 Update. Alcohol Clin Ex Res 1996; 20:138A$46 A * *$.

(23) $\mathrm{Hu} Y$, Ingelman-Sundberg M, Lindros KO. Induction mechanisms of cytochrome P450 2E1 in the liver: Interplay between ethanol treatment and starvation. Biochem Pharmacol 1995; 50: 155-65.

(24) Takahasi T, Lasker JM, Rosman AS, Lieber CS. Induction of P450 E1 in human liver by ethanol is due to a corresponding increase in encoding mRNA. Hepatology 1993; 17: 236-45.

(25) Thurman RG, Handler JA. New perspectives in catalase-dependent ethanol metabolism. Drug Metab Rev 1989; 20: 679-88*. 
(26) Goth L, Pay A. Genetic heterogeneity in acatalasemia. Electrophoresis 1996; 17: 1302-03.

(27) Berkaloff A, Bourguet J, Favard P, Lacroix J. Biología y fisiología celular: Cloroplastos, peroxisomas, división celular. Ed. Omega. Barcelona, 1988.

(28) Yang Q, De Pierre JW. Papid one-step isolation of mouse liver catalase by immobilized metal ion affinity chromatography. Prot Express Purification 1998; 12: 277-83.

(29) Keegan A, Batey R. Dietary carbohydrate accelerates ethanol elimination, but does not alter hepatic alcohol dehydrogenase. Alcohol Clin Exp Res 1993; $17: 431-3$.

(30) Yoshida A, Huang I-Y, Ikawa M. Molecular abnormality of an inactive aldehyde dehydrogenase variant commonly found in Orientals. Proc Nat Acad Sci USA 1984; 81: 258-61.

(31) Farres J, Takahasi K, Cunningham SJ, Wang X, Wang TT, Weiner $\mathrm{H}$. Effects of changing glutamate 487 to lysine in rat and human liver mitocondrial aldehyde dehydrogenase: A model to study human (Orienal type) class 2 aldehyde dehydrogenase. J Biol Chem 1994; 269: 13854-68.

(32) Eriksson CJP. The role of acetaldehyde in the actions of alcohol (update 2000). Alcohol clin Exp Res 2000; 25, 5:15S-32S**.

(33) Raskin NH, Sokoloff L. Enzymes catalyzing ethanol metabolism in neural and somatic tissues of the rat. J Neurochem 1972; 19: 27382.

(34) Lands WEM. A review of alcohol clearance in humans. Alcohol 1998; 15: 147-60*.

(35) Rout UK. Alcohol dehydrogenases in the brain of mice. Alcoholism Clin Exp Res 1992; 16: 286-89.

(36) Gill, K, Menez JF, Lucas D, Deitrich RA. Enzymatic production of acetaldehyde from ethanol in rat brain tissue. Alcohol Clin Exp Res 1992; 16: $910-15$.

(37) Montoliu C, Valles S, Renau-Piqueras J, Guerri C. Ethanol-induced oxygen radical formation and lipid peroxidation in rat brain: effect of chronic alcohol consumption. J Neurochem 1994; 63: $1855-62$.

(38) Smith BR, Aragon CMG, Amit Z. Catalase and the production of central acetaldehyde: A possible mediator of the psychopharmacological effects of ethanol. Addict Biol 1997;2: 277-89*.
(39) Zimatkin SM, Liopo AV, Deitrich RA. Distribution and kineticks of ethanol metabolism in rat brain. Alcohol Clin Exp Res 1998; 22: 1623-27.

(40) Aragon CMG, Stotland LM, Amit Z. Studies on ethanol-brain catalase interaction: Evidence for central ethanol oxidation. Alcohol Clin Exp 1991; Res. 15: 165-69.

(41) Moreno S, Mugnaini E, Ceru MP. Immunocytochemical localization of catalase in the central nervous system of rat. J Histochem Cytochem 1995; 43: 1253-67.

(42) Aragon CMG, Rogan F, Amit Z. Ethanol metabolism in rat brain homogenates by a catalaseH202 system. Biochem. Pharmacol 1992; 44: 93-98.

(43) Zimatkin SM, Deitrich RA. Aldehyde dehydrogenase activities in the brains of rats and mice genetically selected for different sensivity to alcohol. Alcohol Clin Exp Res; 1995; 19: 130006.

(44) Levitt MD, Levitt DG. The critical rol of the rate of ethanol absorption in the interpretation of the studies purporting to demostrate gastric metabolism of ethanol. J Pharmacol Ex Ther 1994; 269: 297-04.

(45) Laposata EA, Lang LG. Presence of non-oxidative ethanol metabolism in humans organs commonly damaged by ethanol abuse. Science 1986; 231: 497-99.

(46) Wrighton SA, Pai JK, Mueller GC. Demonstration of two unique metabolites of arachidonic acid from phobol ester-stimulated bovine lymphocites. Carcinogenesis 1983; 4: 124751.

(47) Omodeo-Sale F, Lindi CL, Palestini P, Maserini M. Role of phosphatidylethanol in membrans. Effects of membrane fluidity tolerance to ethanol and activity of membran bound enzimes. Biochemistry 1991; 30: 2477-82.

(48) Chao HM.. Alcohol and the mystique of flushing. Alcohol Clin Exp Res 1995; 19: 104$09 * *$.

(49) Kupari M, Lindros K, Hillbom M, Heikkilä J, Ylikahri R. Cardiovascular effects of acetaldehyde accumaltion after ethanol ingestion: Their modification by beta-adrenergic blockade and alcohol dehydrogenase inhibition. Alcohol Clin Exp Res 1983;7:283-88.

(50) Inoue K, Fukunaga M, Yamasawa K Accumulation of acetaldehyde in alcohol-sensitive Japanese: Relation to ethanol and acetaldehyde oxi- 
dizing capacity. Alcohol Clin Exp Res 1984;8:319-22

(51) Lindros KO. Acetaldehyde: its metabolism and role in the actions of alcohol. En: Research advances in alcohol and drug problems. 1978; 111-76. Israel, Y. et al., (eds). Plenum. NY.

(52) Aragon CMG, Abitbol M, Amit Z. Acetaldehyde may mediate reinforcement and aversion produced by ethanol. An examination using conditioned taste aversion paradigm. Neuropharmacology 1986; 25: 79-3.

(53) Bergamaschi S, Yoyovoni S, Rius RA, Trabucchi M. Acute ethanol and acetaldehyde administration produce similar effects on L-type calcium channels in rat brain. Alcohol 1988; 5: 337-40.

(54) Zimatkin SM, Deitrich RA. Ethanol metabolism in the brain. Adicction Biol 1997;2:387-399*.

(55) Kuriyama S, Okuma S, Tomono S, Hirouchi M. Effects of alcohol and acetaldehyde on metabolism and function of neurotransmitter systems in cerebral cortical neurons in primary culture. Alcohol Alcohol 1987; spl.1: 685-89.

(56) Poldrugo F, Snead OC. Effect of ethanol and acetaldehyde on gamma-hydroxybutyric acid in rat brain and liver. Subs. Alcohol Actions/Misuse 1985; 5:263-271.

(57) Barbaccia ML, Bosio A, Spano PF, Trabucchi M. Ethanol metabolism and striatal dopamine turnover. J. Neural Transmiss 1982; 53: 169-77.

(58) Pastoric M, Boyadjieva N, Sarkar DK. Comparison of the effects of alcohol and acetaldehyde on proopiomelanocortin mRNA levels and $\beta$ endorphin secretion from hypothalamic neurons in primary cultures. Mol. Cel. Neurosci 1994; 5: 580—586.

(59) Reddy BV, Sarkar DK. Effect of alcohol, acetaldehyde and salsolinol on $\beta$-endorphin secretion from the hypotalamic neurons in primary cultures. Alcohol Clin Exp Res 1993;17: 161-1267.

(60) Reddy BV, Boyadjeva N, Sarkar DK. Effect of ethanol, propanol, butanol and catalase enzyme blockers on $\beta$-endorphin secretion from primary cultures of hypotalamic neurons: Evidence for a mediatory role of acetaldehyde in ethanol stimulation of $\beta$-endorphin release. Alcohol Clin Exp Res 1995;19: 339-344.

(61) Walsh MJ. Role of acetaldehyde in the interactions of ethanol with neuroamines, 233-266. En: Biochemical aspects of alcohol; Roach, M.K. et al. (eds). 1971 University of Texas Press.
(62) Thadani PV Truitt EB. Effect of acute ethanol or acetaldehyde administration on the uptake, release, metabolism and turnover rate of norepinephrine in rat brain. Biochem Pharmacol 1977;26: 1147-1150.

(63) Ortiz A, Griffiths PJ, Littleton JM. A comparison of the effects of chronic administration of ethanol and acetaldehyde to mice: Evidence for a role of acetaldehyde in ethanol dependence. J Pharmacy Pharmacol 1974; 6: 349—60.

(64) Truitt EB Walsh MJ. The role of acetaldehyde in the actions of ethanol. En: The biology of alcoholism, vol.1. 161-195. Kissin, B.; Begleiter, H. (eds.) 1971 New York: Plenum Press.

(65) Zimatkin SM. Histochemical study of aldehyde dehydrogenase in the rat CNS. J Neurochem 1991;56: 1-11.

(66) Mizoi Y, Ijiri I, Tatsuno Y, Kijima T, Fujiwara S, Adachi J, Hishida S. Relationship between facial flushing and acetaldehyde levels after alcohol intake. Pharmacol Biochem Behav 1979;10:300-11.

(67) Gianoulakis C, Dewaele JP, Thavundayil J. Implication of the endogenous opioid system in excesive ethanol consumption. Alcohol 1996;13: 19-3.

(68) Terenius L. Alcohol addiction (alcoholism) and the opioid system 1. Alcohol 1996;13: 31-34.

(69) Takayama S, Uyeno ET. Intravenous self administration of ethanol and acetaldehyde by rats. Japanese J Psychopharmacol 1985;5: 329_ 334.

(70) Myers WD, Ng K, Singer G. Effects of naloxone and buprenorphine on intravenous acetaldehyde self-injection in rats. Phisiol Behav 1984a;33: 807-11.

(71) Myers WD, Ng K, Singer G. Ethanol preference in rats with a prior history of acetaldehyde selfadministration. Experientia 1984b;40: 100810.

(72) Brown ZW, Amit Z, Smith BR. Intraventricular self-administration of acetaldehyde but not ethanol, in naive laboratory rats. Psychopharmacology 1979; 64: 271-76.

(73) Rodd-Henricks ZA, Zaffaroni A, Goldstein A, McBride WJ, Li TK. Alcohol Preferring (P) rats self-administer acetaldehyde directly into the posterior VTA (abstract). Alcohol Clin Exp Res 2000;(Suppl 5) 24:52 A

(74) Myers RD, Veale WL. Alterations in volitional alcohol intake produced in rats by chronic intra- 
ventricular infusions of acetaldehyde, paraldehyde or methanol. Arch. Int. Pharmacodyn 1969;180: 100-13.

(75) Smith BR, Amit Z, Splawinsky J. Conditioned place preference induced by intraventricular infusions of acetaldehyde. Alcohol 1984;1:193-195.

(76) Smith BR, Aragon CMG, Amit Z. A time-dependent biphasic effect of an acute ethanol injection on 3-methoxy 4-hydroxyphenylethylene glycol sulfate in rat brain. Biochem Pharmacol 1985; 34: 1311-14.

(77) Quetermont E, De Witte P. Conditioned stimulus preference after acetaldehyde but not ethanol injections. Pharmacol biochem Behav $2001 ; 68: 449-454$.

(78) Yamauchi M, Maezawa Y, Mizuhara Y, Ohata M, Hirakawa J, Nakajima H, Toda G. Polymorphisms in alcohol metabolizing enzyme genes and alcoholic cirrhosis in Japanese patients. Hepatology 1995; 22: 1136-42.

(79) Higuchi S. Polymorphisms of ethanol metabolizing enzyme genes and alcoholism. Alcohol Alcohol 1994;29:29-34.

(80) Peachey JE, Brien JF, Loomis CW, Rogers BJ. A study of the calcium carbimide-ethanol interaction in man: Symptom responses. Alcohol Clin Exp Res 1980;4:32-329.

(81) Schuckit MA, Duby J. Alcohol-related flushing and the risk for alcoholism in sons of alcoholics. J Clin Psychiatry 1982;43:415-418.

(82) Hunt WA. Role of acetaldehyde in the actions of ethanol on the brain-A review. Alcohol 1996 13: $147-51^{*}$.

(83) Tabakoff B, Anderson RA, Ritzmann, RF. Brain acetaldehyde after ethanol administration. Biochem Pharmacol 1976;25: 1305-1309.

(84) Deitrich RA. The especifity of ethanol. En: Advances on biomedical alcohol research. 1987;131-38. Lindros KO (ed). Pergamon Press, New York, 1987.

(85) Amit Z, Smith BR. A Multi-dimensional examination of the positive reinforcing properties of acetaldehyde. Alcohol 1985; 2: 367-70.

(86) Amit Z, Aragon CMG, Smith BR. Alcohol metabolizing enzymes as possible markers mediating voluntary consumption. Canadian J. Public Health 1986; 77 sup. 1: 15-20.

(87) Amit Z, Smith BR. The role of acetaldehyde in alcohol addiction. Human metabolism of alco- hol. 1989; Vol II; 194-198 Cro, KE, Batt RD. (eds.) CRC Press Inc.

(88) Myers WD, Ng K, Singer G. Intravenous selfadministration of acetaldehyde in the rat as a functions of schedule, food deprivation and photoperiod. Pharmacol Biochem Behav 1982; 17: 807-11.

(89) Kenney WC. Interaction of acetaldehyde with phospholipids. Gastroenterology 1980; 79: 1030-32.

(90) Shiohara E, Tsukada M, Chiba S, Yamazaki H, Nishiguchi K, Miyamoto R, Nakanishi S. Effect if chronic administration of acetaldehyde by inhalation $\left(\mathrm{Na}^{+} \mathrm{K}^{+}\right)$-activated adenosine triphosphatase activity of rat brain membranes. Toxicology 1986;34: 277-284.

(91) Lumeng L, Lin, RC. Protein acetaldehyde aducts as biochemical markers of alcohol consumption. En: Measuring alcohol consumption. 1992; 161-82; Litten, R. (ed). The Humana press Inc.

(92) Jennet RB, Sorrell MF, Saffari-Fard A, Ockner JL Tuma DJ. Preferential covalent binding of acetaldehyde to the $\alpha$-chain of purified rat liver tubulin. Hepatology 1989; 9: 57-2.

(93) Nuñez-Vergara LJ, Yudelevich J, Squella JA Speisky $H$. Drug-acetaldehyde interactions during ethanol metabolism in vitro. Alcohol Alcohol 1991; 26:139-46.

(94) Deitrich RA, Erwin VG. Interaction of amine metabolism and alcohol actions. En: Monoamine oxidase and disease, 275-89. Academic Press, New York, 1984.

(95) Rommelspacher H, Buchau C, Weiss J. Harman induces preference for ethanol in rats: Is the effect specific for ethanol?. Pharmacol Biochem Behav 1987;26: 749-755

(96) Brown ZW, Amit Z, Smith BR. Intraventricular self-administration of acetaldehyde and voluntary consumption of ethanol in rats. Behav. Neural Biol 1980; 28: 150-55.

(97) Smolen TN, Collins AC. Behavioral effects of ethanol and salsolinol in mice selectively bred for acute sensivity to ethanol. Pharmacol Biochem Behav 1984;20:281-28.

(98) Lieber CS. Mechanisms of ethanol-drug-nutrition interactions. J Toxicol Clin Toxicol 1994;32:631-81.

(99) Nordmann R. Alcohol and antioxidant systems. Alcohol 1994; 29:513-22. 
(100) Lieber CS. Cytochrome P-250 2E1: Its Physiological and pathological role. Physiol Rev 1997; 77:517-44*.

(101) Goldberg DM, Parkes JG, Hahn S. Microsomal induction, alcohol, and lipoprotein metabolism: Is there a three-way relationship?. Clin Biochem 1989; 22:57-7*.

(102) Hoensch H. Ethanol asenzyme inducer and inhibitor. Pharmac Ther 1987; 33;12-8.

(103) Koop DR, Coon MJ. Ethanol oxidation and toxicity: Role of alcohol P-450 oxygenase. Alcohol Clin Exp Res 1986; 10:44S—8S.

(104) Djordjevic D, Nikolic J, Stefanovic V. Ethanol interactions with other cytochrome P450 substrates, drugs, xenobiotics, and carcinogens. Pathol Biol 1998; 46:760-70*.
(105) McClain CJ, Kromhout JP, Peterson FJ Holtzman JL. Potentiation of aetaminophen hepatotoxicity by alcohol. JAMA 1980; 244:251-3.

(106) Banda PW, Quart BD. The effect of alcohol consumption on the metabolism of acetaminophen in man. Res Commun Pathol Pharmacol 1982; 38:57-0

(107) Duester G. Alcohol dehydrogenase as a critical mediator of retinoic acid synthesis from vitamin A in the mouse embryo. J Nutr 1998; 128:459S-62S.

(108) Leo MA, Lieber CS. Alcohol, vitamin A, and bcarotene: Adverse interactions, including hepatotoxicity and carcinogenicity. Am J Clin Nutr 1999; 69:1071-85*. 